\title{
EFECTOS EMBRIOTÓXICOS DE Picrosia Iongifolia DON (ASTERACEAE)
}

\section{EMBRYOTOXIC EFFECTS OF Picrosia longifolia DON (ASTERACEAE)}

\author{
Víctor Benavides, Guadalupe D'Arrigo y José Pino*
}

\section{RESUMEN}

Se ha evaluado los probables efectos tóxicos del extracto acuoso de Picrosia longifolia Don "Achicoria" sobre el desarrollo de embriones preimplantacionales de ratón. Extracto acuoso de P. Iongifolia al $20 \%, 10 \%$ y $0 \%$ fue suministrado a ratonas preñadas hasta las 86 horas postcópula (hpc). Al evaluar el estadio embrionario se encontró que el extracto acuoso de $P$. longifolia al $10 \%$ y $20 \%$ causó retraso en el desarrollo embrionario. También se observó una disminución en la viabilidad embrionaria en los grupos tratados. Tanto la disminución de viabilidad como el retraso en el desarrollo se produjo en una forma dosis dependiente.

\section{ABSTRACT}

The toxic effects of aquous extract of Picrosia longifolia Don "achicoria" on preimplantational mouse embryo development were evaluated. Aquous extract of $P$. longifolia to $20 \%, 10 \%$ and $0 \%$ (control group) was supplied to pregnant mice to 86 hours post-copula (hpc). When embryonic stage was evaluated, we found that aquous extract of $P$. longifolia to $10 \%$ and $20 \%$ causes delay in embryo development. Also the embryonic viability declined in treated groups with achicoria.

Actualmente existe una mayor aceptación de la medicina natural como alternativa para tratar diversas afecciones, empleando preparaciones de plantas medicinales (Trujillo et al., 2000; Benavides et al., 2000).

$P$. longifolia es una planta nativa de América del Sur usada en la medicina natural como refrigerante en los estados febriles y en trastornos intestinales (Sagástegui, 1973). Existen muchos trabajos con plantas medicinales en los cuales no se evalúa los posibles efectos secundarios que puedan aquellas a nivel de toxicidad general ni los efectos de su ingesta durante el período de gestación. El estudio de los embriones preimplantacionales para el en-

* Laboratorio de Reproducción y Biología del Desarrollo, Facultad de Ciencias Biológicas-UNMSM. Av. Venezuela s/n. Casilla Postal 14-002, Lima 14, Perú.E-mail:vbenavides23@hotmail.com tendimiento del mecanismo de embriotoxicidad en estadios tempranos de la gestación ha generado nuevas perspectivas sobre la acción de drogas y tóxicos ambientales (Del Valle \& Orihuela, 1996).

En el presente trabajo se ha evaluado los efectos embriotóxicos del extracto acuoso de $P$. longifolia en embriones preimplantacionales de ratón.

La planta fue obtenida de los mercados de Lima e identificada mediante las claves vigentes. En el laboratorio se procedió al secado (colocándolas en la estufa a $60^{\circ} \mathrm{C}$ durante $24 \mathrm{~h}$ ). Se usaron ratones Albino-Swiss mantenidos en nuestro laboratorio bajo condiciones de bioterio de 14 horas luz y 10 oscuridad. Hembras de 6 a 8 semanas de edad fueron superovuladas inyectándoles intraperitonealmente 5 UI de PMSG y 48 horas después se le inyectó 5 UI de HCG. Luego fueron cru- 
Tabla 1. Efectos del extracto acuoso de achicoria en la morfología embrionaria, expresado en porcentajes.

\begin{tabular}{lcccc}
\hline & Grado 1 & Grado 2 & Grado 3 & Degenerado \\
\hline Control & $66,89(99)$ & $18,92(28)$ & $8,11(12)$ & $6,08(9)$ \\
Grupo A & $21,01(25)^{*}$ & $29,41(35)^{* *}$ & $15,13(18)^{*}$ & $34,45(41)^{*}$ \\
Grupo B & $37,11(36)^{*}$ & $-20,62(20)$ & $30,93(30)^{*}$ & $11,34(11)^{*}$ \\
\hline
\end{tabular}

Los asteriscos designan diferencias significativas entre el control y los grupos tratados $\left({ }^{*} \mathrm{p}<0,005\right.$, $* * *<<0,025)$

Los números en paréntesis representan la cantidad de embriones evaluados.

zadas con machos fértiles de 8 a 12 semanas de edad, comprobándose la cópula al día siguiente por la presencia del tapón vaginal. Las hembras preñadas fueron separadas en tres grupos: Grupo control (Achicoria 0\%, al que se le suministró diariamente ad libitum agua potable); Grupo A y Grupo B, a los demás grupos se les suministró una infusión al 20\% y al $10 \%(\mathrm{p} / \mathrm{v})$ de Achicoria. El extracto acuoso al $20 \%$ y $10 \%$ fue preparado colocando $2 \mathrm{~g}$ y $1 \mathrm{~g}$ respectivamente de la planta seca en 10 $\mathrm{mL}$ de agua potable previamente calentada a $60^{\circ} \mathrm{C}$; se dejó en infusión durante 15 minutos más a la misma temperatura; se dejó enfriar y decantar; luego se separó el sobrenadante, el cual fue suministrado a los animales en las mismas condiciones que el grupo control, hasta las 86 horas postcópula (hpc). La infusión fue renovada diariamente. Las hembras fueron sacrificadas por dislocación cervical, y se les extirparon los oviductos y los cuernos uterinos; luego los embriones fueron obtenidos por perfusión, mediante lavados sucesivos con Buffer Fosfato Salino (PBS; SIGMA) $\mathrm{pH} 7,4$. Los embriones se examinaron en un microscopio de contraste de fase y se determinó el grado de viabilidad realizando una evaluación morfológica considerando lo si- guiente (4): Grado 1: el embrión es redondo y no tiene blastómeros libres; Grado 2: E] embrión tiene blastómeros libres; Grado 3: el embrión tiene blastómeros libres y malformaciones severas; Degenerados: el embrión pierde su forma esférica, además presenta membrana(s) celular(es) rotas. Se evaluó un total de 364 embriones divididos como sigue: Grupo control 148 embriones, Grupo A 119 y Grupo B 97. A los resultados se les aplicó la prueba de $\chi^{2}$.

Los resultados obtenidos evidencian una mayor incidencia de alteraciones morfológicas en los embriones tratados con la infusiones de achicoria, observándose una disminución de embriones de grado 1 en los grupos A y B donde se encontró $21,01 \%$ y $37,11 \%$ respectivamente mientras que en el grupo control se registro 66,89\% de embriones de Grado 1 y como consecuencia de esto se observa un incremento de embriones de Grado 2 y 3 y de embriones degenerados en los grupos tratados con achicoria contrastado con el grupo control (Tabla 1). En cuanto al estadio de desarrollo se observa un retraso en el desarrollo evidenciado por el incremento en el número de embriones de 1 -8 células y mórulas encontrados en los grupo A y $\mathrm{B}$ con respecto al gru-

Tabla 2. Efecto sobre la distribución de los estadios de desarrollo en porcentajes.

\begin{tabular}{lccc}
\hline & $\mathbf{1 - 8}$ células & Mórula & Blastocisto \\
\hline Control & $8,78(13)$ & $14,86(22)$ & $76,35(113)$ \\
Grupo A & $37,82(45)^{*}$ & $26,05(31)^{*}$ & $36,13(43)^{*}$ \\
Grupo B & $12,37(12)$ & $39,18(38)^{*}$ & $48,45(47)^{*}$ \\
\hline
\end{tabular}

Los asteriscos designan diferencias significativas entre el control y los grupos tratados ( $\mathrm{*} p<0,005)$.

Los números en paréntesis representan la cantidad de embriones evaluados. 
po control y a su vez se registró una disminución de embriones en estadio de blastocisto siendo en el grupo A y B $50,42 \%$ y $48,41 \%$ respectivamente, mientras que en el grupo control se registró $76,35 \%$, siendo estas diferencias significativas (Tabla 2 ).

Existen muy pocos reportes científicos sobre las propiedades y efectos tóxicos de $\mathrm{P}$. longifolia. Nuestros resultados evidencian una disminución en la viabilidad del embrión debido al aumento en la frecuencia de embriones de grado 3 y embriones degenerados en los grupos A y B, y a su vez también se ha observado un retraso en el desarrollo embrionario. La disminución en la formación de blastocisto puede estar relacionada con el decrecimiento de la proliferación celular, lo que incrementaría la cantidad de embriones retrasados (Orihuela e Ishiyama, 1991)

Los resultados obtenidos en este trabajo evidencian un fuerte potencial embriotóxico del extracto acuoso de $P$. longifolia en embriones preimplantacionales de ratón.

\section{LITERATURA CITADA}

Sagástegui Alva, A.1973. Manual de las malezas de la Costa Nor Peruana. Universidad Nacional de Trujillo, Perú.
Del Valle, L. and P. Orihuela. 1996a. Cleavage and development in cultured preimplantation mouse embryos exposed to lidocaine. Reprod Toxicol $10(6): 1-6$.

Del Valle, L and P. Orihuela. 1996b. Prolonged exposure to lidocaine disturbs preimplantation mouse embryo development. Reprod Toxicol 10 (2): 113-118.

Dorn C. G. \& D. C. Kramer. 1987. Bovine embryo grading. Texas A \& E University, USA.

Hogan B.; F. Constantini \& E. Lacy. 1986. Manipulating the mouse embryo. A laboratory manual. USA. Cold Spring Harbor Laboratory.

Orihuela P. y V. Ishiyama. 1991. Efectos embriotóxicos de Erithrina falcata Benth (Familia Fabaceae). Bol. Lima. 76: 49-52.

Trujillo G.; V. Benavides y J. Pino. 2000. Efecto in vivo de Persea americana "palta" (Lauaracea) en el desarrollo de embriones preimplantacionales de ratón. Libro de resúmenes IX Reunión Científica del Instituto de Investigación de Ciencias Biológicas "Antonio Raimondi”, pp. 43, Lima-Perú.

Benavides V.; G. Trujillo; G. D'Arrigo; U. Paredes y J. Pino. 2000. Evaluación toxicológica preliminar de Ruta graveolens, Origanum vulgare y Persea americana sobre embriones preimplantacionales de ratón. Rev. peru. biol 7: 86-88. 